\title{
CHIP EVACUATION OF PCB MICRO-DRILLING AND HIGH-SPEED PHOTOGRAPHY
}

\author{
Zihao Ding ${ }^{1}$, Lixin Huang ${ }^{2}$ \\ ${ }^{I}$ Department of Mechanical and Automobile Engineering, Shanghai University of Engineering Science, Shanghai, \\ China \\ ${ }^{2}$ Department of Mechanical and Automobile Engineering, Shanghai University of Engineering Science, Shanghai, \\ China
}

\begin{abstract}
Chip evacuation is one of the essential indicators reflecting the quality of drilling of printed circuit board (PCB). Thrust force variation shows the chip evacuation condition as drilling depth increases. This paper aims to describe the chip evacuation, thrust force and force generation mechanism. The goal is to provide thrust characteristics which can reflect chip evacuation performance. The chip evacuation is observed and recorded through high-speed photography technology. The thrust force of single and multiple drilling procedures of two materials is gauged with dynamometer. Curling is main deformation of copper and aluminium chips. The main evacuation form of chips is spiralling up along the flute. Maximum thrust force appears when drilling top copper foil. When the thrust force of multiple hole drilling is stable, the hole accuracy meets the requirement of production. This paper analyses chip evacuation in PCB micro-drilling. The process of chip evacuation is captured by high-speed camera. The relationship between hole accuracy and thrust force is illustrated.
\end{abstract}

\section{INTRODUCTION}

As the foundation for the electronic components to assembly and integrate, printed circuit board (PCB) is being utilized in electronic industry widely. Micro hole is the essential structure in PCB, which can be categorized into PTH (Plated Through Hole) and Non-PTH. PTH includes holes for IC pins and via holes connecting different layers. Copper on the hole walls is plated to conduct mid layer or conductive patterns on the outer layer; Non-PTH includes the holes that fix cards and there is no copper on the hole wall.

In current production, micro holes above $0.3 \mathrm{~mm}$ are mechanically processed with NC drilling machine. $80 \%$ of the micro holes under $0.1 \mathrm{~mm}$ are machined with $\mathrm{CO} 2$-laser drilling machine. Diameter of $65 \%$ of micro-drills are under $0.3 \mathrm{~mm}$ in the mechanical drilling. The method has advantages of higher efficiency and lower cost on laser micro-drilling. However, short lifespan and frequent changing of tools mainly restrain productivity and profit growth potential. Blocked chip is the primary cause for drill breakage and abrasion. Bad chip evacuation affects the hole quality and accuracy greatly as well. During tooling process, chip evacuation condition varies as thrust force changes.

Shi et al. (2017) studied characterization of drill breakage when drilling FR-4 with high-speed video method, and found that blocked chips is the main cause of the drill breakage. Drill may be fractured when radians of swing angle excesses range of \pm 0.01 . Mellinger et al. (2002) believed that pressure on the chips is created by the force that push the chips out of the hole. A model of chipevacuation force is developed to predict chip-clogging in the chip evacuation. The characteristics of the thrust force was divided into two components, the static component and the dynamic component, chisel edge affects the static component, while the major cutting edge of the drill is influential in dynamic component (1997; Ogawa et al.). Watanabe et al. (2008) used the $0.1 \mathrm{~mm}$ diameter drills to drill the PCB at $300 \mathrm{~K} \mathrm{rpm}$ spindle speed. The workpiece were four pieces of double-sided PCB board (overall thickness $0.1 \mathrm{~mm}$, copper foil thickness $0.6 \mu \mathrm{m}$ ), and the drilling behavior at contact with the workpiece surface was dynamically observed using a high-speed video camera so as to research the influence of radial run-out of micro-drills on hole quality (hole location accuracy, enlargement error of hole diameter, burr height and hole wall roughness).

The objective of this paper is to analyze the characteristic, generation mechanism of thrust force, its effect on the chip evacuation during the processing and the factors affecting the relationship in micro-drilling through experimentation. Paper also illustrates how thrust and chip evacuation affect the hole quality and thrust force patterns which can reflect condition of chip evacuation.

\section{EXPERIMENTATION}

\subsection{Printed Circuit Board}

The main workpieces of drilling experimentation are glass cloth base Cu-clad laminate FR-4 and halogen free (HF) board which are common in PCB production. 
FR-4 board uses epoxy resin as adhesive and electronicgrade glass fiber cloth as reinforcement. It is flame retardant and insulated. Bonding sheet and $\mathrm{Cu}$-clad laminate of inner core are important materials to manufacture multi-layer PCB. Products demanding highperformance electronic insulation can apply FR-4 in them. $\mathrm{HF}$ board is a halogen-free $\mathrm{Cu}$-clad laminate with the content of Chlorine $(\mathrm{Cl})$ and the content of Bromine $(\mathrm{Br})$ less than 0.09 per cent weight, respectively. The board performance is shown in Table I.

There are two kinds of conductive $\mathrm{Cu}$-clad foils:

1. Rolled $\mathrm{Cu}$ foil; and

2. Electrolytic $\mathrm{Cu}$ foil.

Rolled $\mathrm{Cu}$ foil requires a high purity of $\mathrm{Cu}$ (generally $\geq$ 99.9\%) and good elasticity. It is applicable for producing high-performance PCBs such as flexible plate and highfrequency signal plate. Electrolytic $\mathrm{Cu}$ foil is used for producing ordinary PCB and its purity is slightly lower than that of rolled $\mathrm{Cu}$ foil. The $\mathrm{Cu}$ foil used in this research is specified as: thickness $0.035 \mathrm{~mm}$; weight per unit area $\geq$ $280-305 \mathrm{~g} / \mathrm{m} 2$; purity $\geq 99.8 \%$; strength of extension (room temperature) $\geq 30 \mathrm{~N} / \mathrm{mm} 2$; elongation (room temperature) $\geq 5$ per cent. The entry board in the experimentation is made of pure aluminum plate.

Table-1: Specification of PCB

\begin{tabular}{|c|c|c|c|c|c|}
\hline & $\begin{array}{l}\text { Board } \\
\text { thickne } \\
\text { ss } \\
(\mathbf{m m})\end{array}$ & $\begin{array}{l}\text { Coppe } \\
\mathbf{r} \\
\text { clad } \\
(\mu \mathrm{m})\end{array}$ & $\begin{array}{l}\text { Glass } \\
\text { transition } \\
\text { temperatu } \\
\text { re } \\
\mathrm{Tg}\left({ }^{\circ} \mathrm{C}\right)\end{array}$ & $\begin{array}{l}\text { Peel } \\
\text { strengt } \\
\text { h } \\
(\mathrm{kg} / \mathrm{cm} \\
\text { ) }\end{array}$ & $\begin{array}{l}\text { Bendin } \\
\text { g } \\
\text { strengt } \\
\text { h } \\
\text { (Mpa) }\end{array}$ \\
\hline $\begin{array}{l}\text { FR } \\
-4\end{array}$ & 1.6 & 35 & 130 & $\begin{array}{l}160 \sim 23 \\
0\end{array}$ & $\begin{array}{l}450 \sim 60 \\
0\end{array}$ \\
\hline $\mathrm{HF}$ & 1.6 & 35 & 170 & $\begin{array}{l}140 \sim 15 \\
0\end{array}$ & $\begin{array}{l}476 \sim 56 \\
1\end{array}$ \\
\hline
\end{tabular}

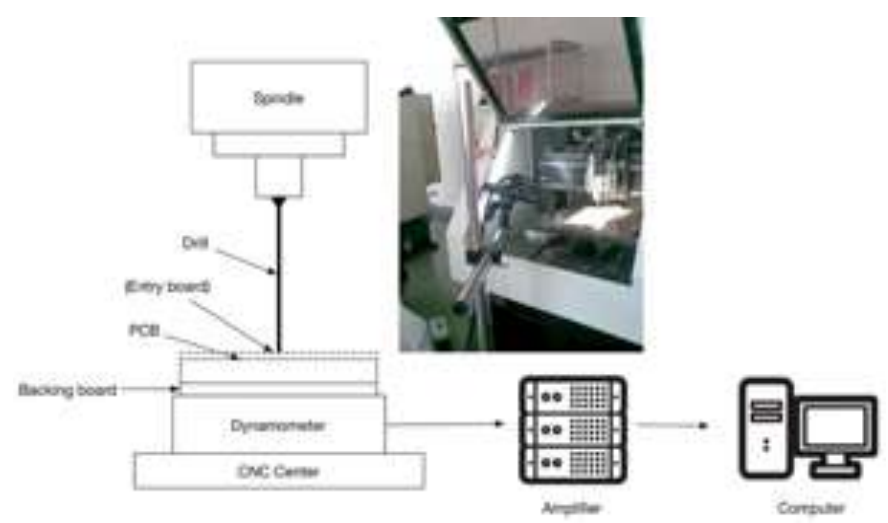

Fig 1: The setup of drilling experimentation

\subsection{PCB Drill}

The PCB drills are manufactured by HPTec China (Kunshan) Co., Ltd. Point angle of the drills is $130^{\circ}$ and helix angle is $30^{\circ}$. Drill structure is shown in Figure 2.

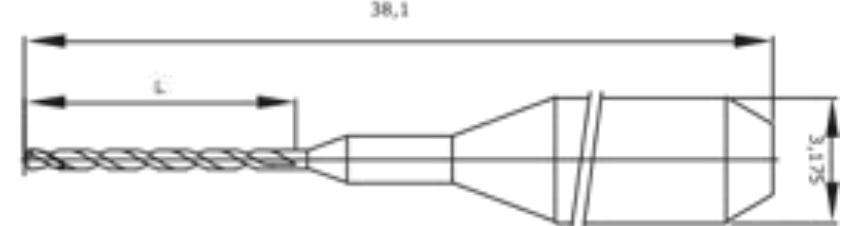

Fig 2: The structure of the micro-drill

\subsection{High-Speed Image Capture Technology}

The transient process state is recorded with the high-speed image capture technology. Photographs are taken with a Fastec Hispec 5 high-speed camera. The image capture frequency is 1,000 frame per second.

\section{THRUST FORCE OF CHIP EVACUATION}

\subsection{Thrust Force with no Entry Board of Chip}

\section{Evacuation}

Drilling experiments without entry board are performed both on FR-4 and HF board. The thickness of FR-4 is $1.6 \mathrm{~mm}$ and drill diameter is $0.3 \mathrm{~mm}$. Spindle speed is $75 \mathrm{~K}$ $\mathrm{rpm}$ and feed rate is $\mathrm{Vf}=55 \mathrm{~mm} / \mathrm{min}$.

Time of drilling entry board:

$$
\mathrm{t}_{1}=\frac{0.2 \mathrm{~mm}}{55 \mathrm{~mm} / \mathrm{min}}=\frac{0.2 \mathrm{~mm}}{55 \times \frac{10 \mathrm{~mm}}{60 \mathrm{~s}}}=0.021818 \mathrm{~s} \#(1)
$$

Time of drilling FR-4:

$$
\mathrm{t}_{2}=\frac{1.6 \mathrm{~mm}}{55 \mathrm{~mm} / \mathrm{min}}=\frac{1.6 \mathrm{~mm}}{55 \times \frac{10 \mathrm{~mm}}{60 \mathrm{~s}}}=0.174545 \mathrm{~s} \mathrm{\# (2)}
$$

The dynamic thrust force plot of micro-drilling FR-4 process is shown in Figure 3(a). Thrust force characteristics of drilling process is divided into three phases by drilling depth.

Process starts with drilling top copper foil in first phase. Thrust force peak occurs in the first phase, which reaches $2.06 \mathrm{~N}$, is the drilling maximum axial force of the process. The peak is dramatically higher than the other curve occurred in the third phase. Compared with regular drill, micro-drill has less rigidity due to its small diameter. When drill point contacts workpiece, drill has less resistance to the impact. Lack in rigidity makes drill deform more and generate more thrust force than it does under the stable circumstance. Besides, $\mathrm{Cu}$ is a kind metal that has good toughness. These two features mainly caused boost of thrust force peak in drilling top copper foil.

The second phase is drilling of compound layer of resin and glass fiber cloth. Thrust force drops instantly and keeps decreasing in this period. Thrust force fluctuates harder compared to drill with large diameter in this phase. While large drill cuts the whole strand of glass fiber in cloth, 
micro-drill is only able to cut few threads of one strand of glass fiber. Glass fiber is a kind of brittle material. Diameter of glass fiber is around $10 \mu \mathrm{m}$ or less. Thrust force decreases immediately the moment glass fiber broke, which brings strong fluctuation of thrust force.

The third phase of process is drilling bottom copper foil and paper back up board. The force peak occurred in this phase is around $1.23 \mathrm{~N}$, which is nearly half of the first peak. At this time, drill is restricted by layer of glass fiber and resin which provides a more rigid condition for drilling. So, less impact is gained and less counterforce does bottom copper supply. So, thrust force value curve is relatively lower at this phase.

Experiment is also performed with same parameter and a drill diameter of $1 \mathrm{~mm}$. The plot is shown in Figure 3(b). The drilling process is also divided into three phase. Trend of the whole thrust force and shift pattern of each phase are similar to the previous pattern, which is shown in Figure 3. The drilling maximum force is $3.29 \mathrm{~N}$, which is higher than the maximum force of drilling with drill of $0.3 \mathrm{~mm}$ diameter. This indicates that thrust force increases as drill diameter increases.

Processing of HF board is carried out with same spindle speed and double feed rate. As shown in Figure 3(e), the plot resembles the plot of FR-4 with and without entry board. However, the whole magnitude is lower than FR-4.

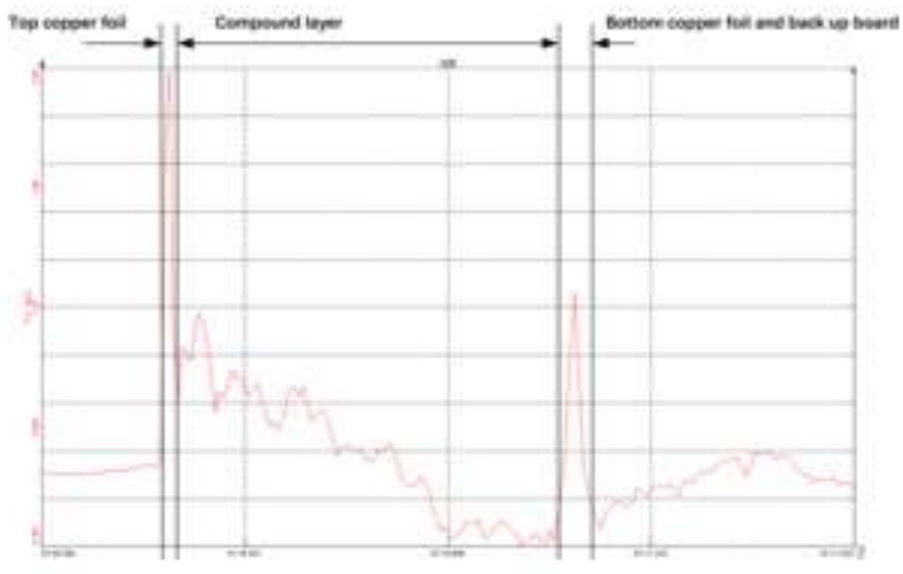

(a)

\subsection{Thrust Force with Entry Board of Chip Evacuation}

The thrust force plot of process with pure aluminum plate entry board is shown in Figure 3(c). Workpiece is processed with the $1 \mathrm{~mm}$ drill. The whole trend is similar to the drilling with no entry board. In addition, phase of drilling pure aluminum entry board is added to three original phases of thrust force plot. The drilling maximum force in this phase is $1.46 \mathrm{~N}$. A drop is followed before entering the phase of drilling top copper foil which is caused by the gap between entry board and PCB.

\subsection{Influence of Entry Board on Thrust Force of}

\section{Chip Evacuation}

Whole process lasts longer than the one without entry board due to the gap between pure aluminum plate entry board and PCB. Machining with entry board is more stable than drilling process without entry board. Particularly in the phase of processing compound layer of glass fiber and resin. Drilling axial force in this phase fluctuates less with entry board. Same pattern occurred when drilling HF board as shown in Figure 3(d).

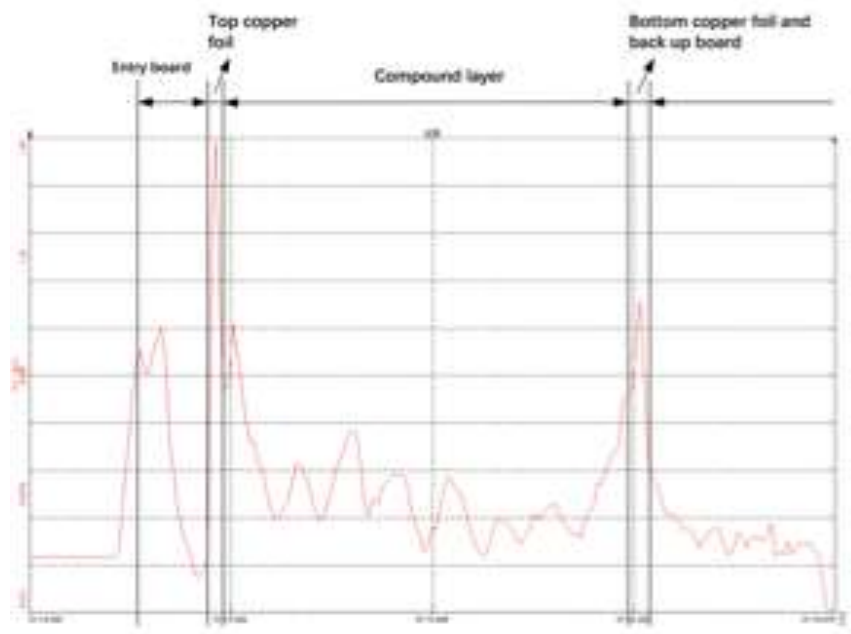

(b) 


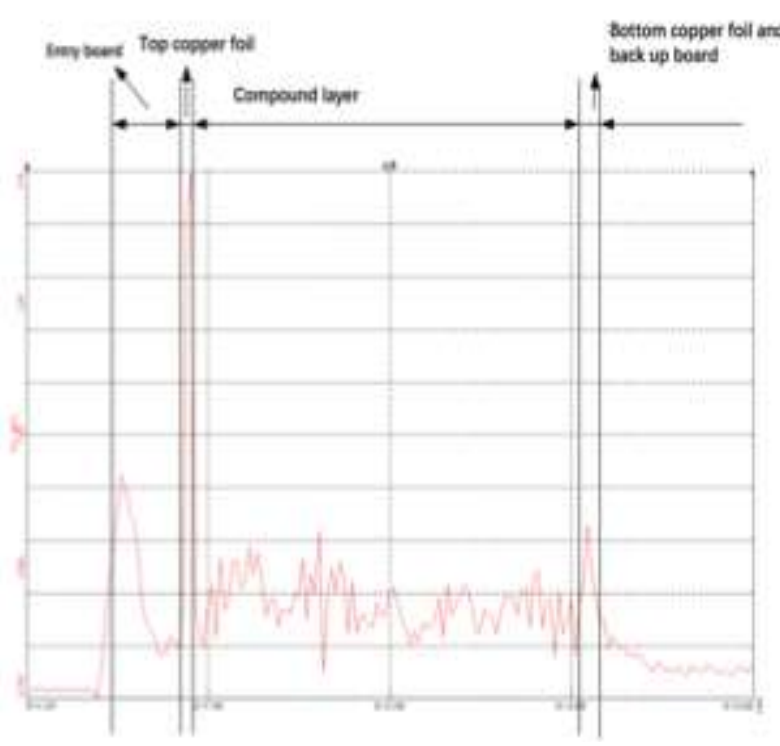

(c)

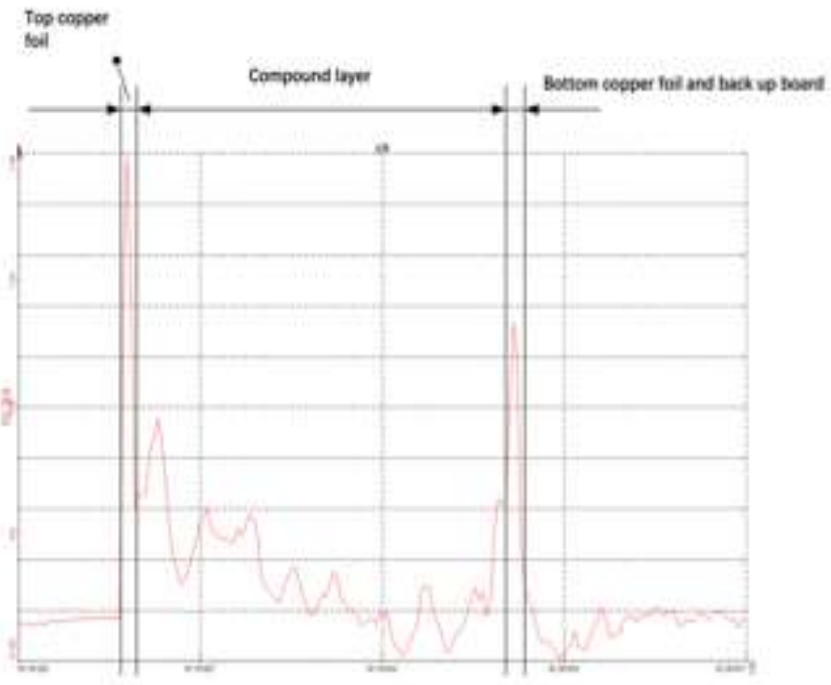

(d)

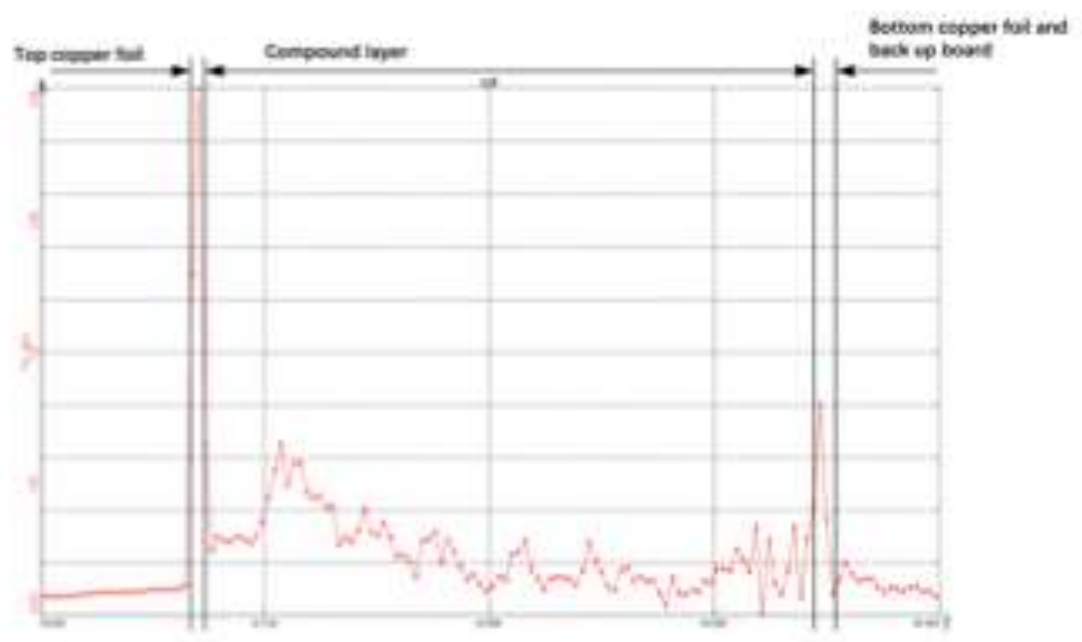

(e)

Fig-3: Thrust force plot of chip evacuation

Note: $n=75 \mathrm{k} . r p m$ (a) $\mathrm{D}=0.3 \mathrm{~mm}$; vf=55cm/min; FR-4; (b) $\mathrm{D}=1 \mathrm{~mm}$; FR-4; (c) $\mathrm{D}=1 \mathrm{~mm}$; entry board; FR-4; (d) D=0.3mm; entry board; HF; (e) $\mathrm{D}=0.3 \mathrm{~mm}$; $\mathrm{HF}$

\section{HIGH-SPEED PHOTOGRAPHY ANALYSIS OF CHIP EVACUATION}

\subsection{Chip Evacuation Movement}

The whole process of chip evacuation is recorded in highspeed photography by the sequence of time. Formation and trajectory of chips are shown in Figure 4. At 38.503ms, drill contacted aluminum entry board and started to drill entry board. After main cutting edges contacted entry board, aluminum begins to form continuous chip under the pressing of rake faces. Then, chip curves and being pushed upward by the newly generated chip simultaneously. Spiral aluminum chip moves upward through the flute and leaves the drill when it is around $3 \mathrm{~mm}$ high from entry board as shown in Figure 4(a). Afterwards, drill started to process the top copper foil at $39.216 \mathrm{~ms}$, which can be judged by the copper chip appeared with aluminum chip in helix groove which is shown in Figure 4(b). Copper foil generates chip after being cut by chisel edge and main cutting edges. Chip curves and then breaks due to the gravity. Compared to aluminum, copper chip leave flute in C-type shape form and being casted out immediately as shown in Figure(e) at $44.207 \mathrm{~ms}$. 


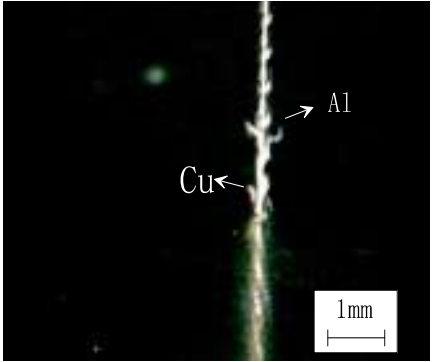

(a)

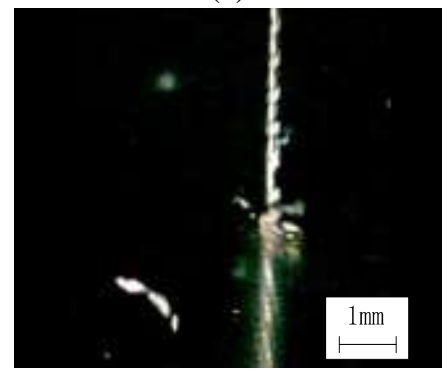

(d)

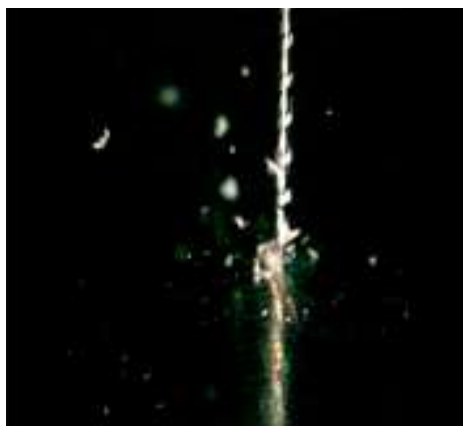

(a)

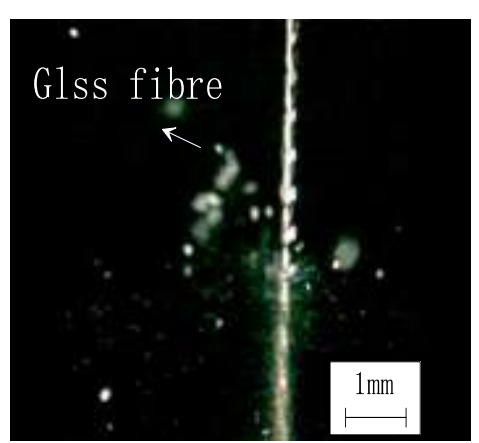

(i)

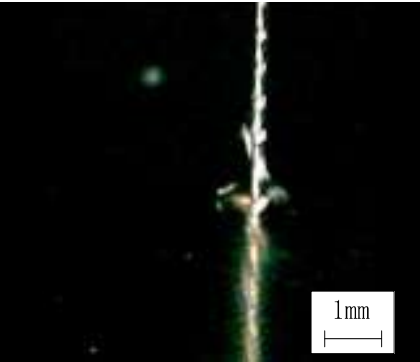

(b)

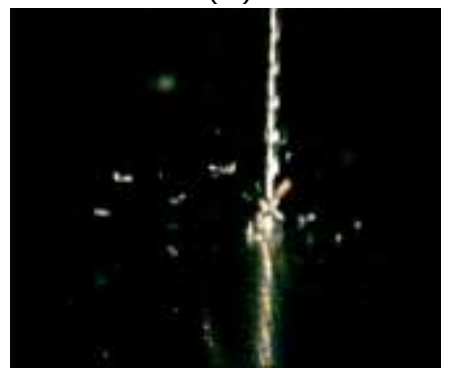

(e)

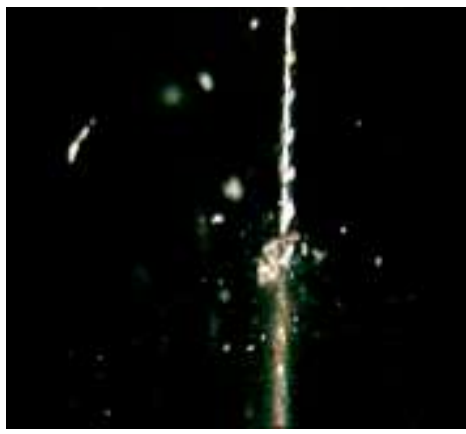

(h)

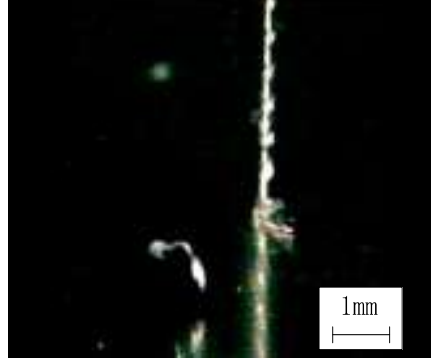

(c)

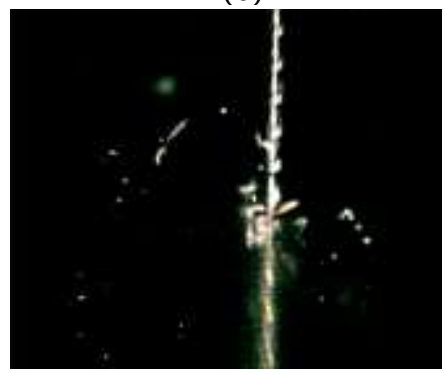

(f)

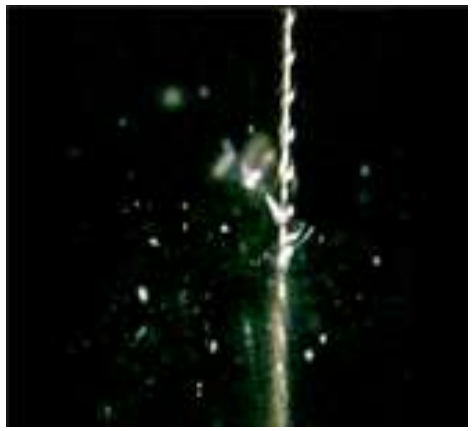

(i)

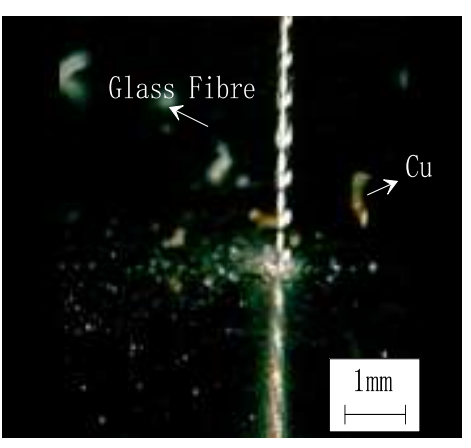

(k)

Fig-4: High-speed photography of chip evacuation

Note: $\mathrm{D}=0.3 \mathrm{~mm} ; \mathrm{n}=75 \mathrm{k} . \mathrm{rpm} ; \mathrm{vf}=55 \mathrm{~cm} / \mathrm{min} ; \mathrm{FR}-4$; entry board;

(a) $38.503 \mathrm{~ms}$; (b) $39.216 \mathrm{~ms}$; (c) $41.355 \mathrm{~ms}$; (d) 42.068ms; (e) 44.207ms; (f) 45.633ms; (g) 47.772ms; (h) 48.485ms; (i) 52.050ms; (j) $64.884 \mathrm{~ms}$; (k) $0.270232 \mathrm{~s}$

In Figure 4(j) shows the machining procedure of composite layer of resin and glass fiber started at $64.884 \mathrm{~ms}$. Mixed chip is casted out in the range of $2.5 \mathrm{~mm}$ at initial stage. Exit height and casting range increased at end stage due to the chip movement velocity increasing at $67.032 \mathrm{~ms}$. Resin is tending to become soft and adhesive after being heated. Adhesive resin chip stick with glass fiber chip together and generate mixed chip. 
Drill exits from workpiece at 0.270232 s as shown in Figure 4(k). Copper chip on the hole exit, which was in short strip shape, and glass fiber chip was carried up by the drill and pitched out from flute.

As distance of chip separates, aluminum chips travel the minimum range, composite chips moves farthest and copper chips are the medium. The angle between aluminum chips and drill axis is the smallest. After clinging to the helix groove, aluminum chips leave the drill. Copper chips leave the flute as soon as they flowed out. Composite chips float away after being evacuated.

As form of chip, composite chips are rather short and very soft, medium length of copper chips, aluminum chips the length of the shortest, and was curled-type. Copper chips have type of short strip and C-type. Glass fiber/resin chips have types of granular and separated chips. Different size and ship are produced through the helix groove of the drill when cutting. Great deformation first by the tension cracks and then enlarges the cracks to break down, which become various crack ships (strip, C-type). Slight entanglement of aluminum chip happens at the initial stage of drilling entry board. However, using entry board can alleviate the impact when processing copper foil.

\subsection{Relationship between Thrust Force and Chip}

\section{Evacuation}

Four type of waveform of thrust force in the plot shows up as follows: wide stinger, long stinger, saw slope and short stinger. They can be categorized according to stage machining carried out and each waveform can reflect corresponding chip evacuation.

Wide stinger happens when using aluminum entry board. Aluminum has good ductility and low hardness. Thrust force is going to be lower with entry board. Since certain gap exists between entry board and PCB, it takes longer to drill the entry board than drilling without one, which makes stinger wider. A force valley follows the wide stinger for the same reason. Short strip type chip generation is usual in this period due to the high spindle speed. Chip tends to leave the flute after ascending to the certain height which is another reason that the stinger is wide.

Long stinger wave appears when drilling top copper foil. Main cause is impact drill point received at the entry period. Applying entry board can reduce the force effectively. Copper chip leaves drill as soon as it exits the drilled hole. Evacuation distance is larger than aluminum chip.

Saw slope emerges when processing composite layer of resin and glass fiber. Random arrangement of the glass fiber leads to the fluctuation of thrust force which shows in plot is thrust force line in the shape of saw. More radial support does drill gain and less axial support as drilling depth increases, which causing thrust force decreasing and makes thrust force line a descending slope.

Short stinger shows up when machining the bottom copper foil and paper back-up. Due to the thickness and material characteristics, thrust force line is also a thin stinger type. Yet, paper back-up is not able to provide as much support as composite layer do. Thrust force is lower than top copper foil which is around half of top foil. Paper chip and part of copper exits from bottom of the drilled hole, and the rest of copper chip is carried by drill and being pitched out.

\section{HOLE ACCURACY AND MULTIPLE THRUST FORCE OF CHIP EVACUATION}

In Figure 6 shows the hole accuracy of FR-4. Machining used the $0.3 \mathrm{~mm}$ micro-drill and aluminum entry board. CPK reaches 1.687 when thrust force fluctuates less than $6 \%$ in the multiple hole drilling process as shown in Figure 6. Stability of thrust force indicates that the chip evacuation is stable and unblocked which provides drill has less opportunity to slide away due to the chip-clogging.
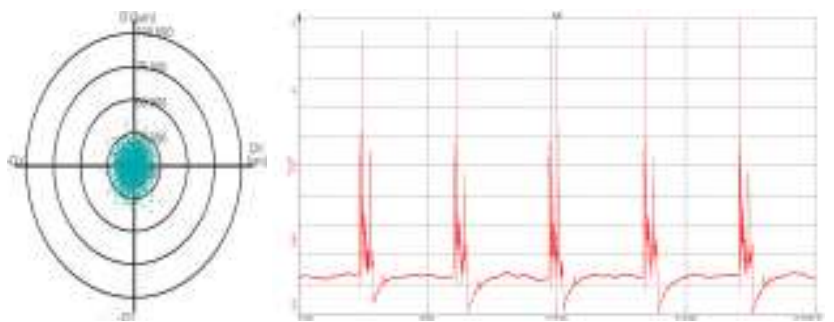

Fig-6: Hole accuracy and multiple hole drilling thrust force

\section{CONCLUSION}

The specific conclusions of this paper can be summarized as follows:

Copper and aluminum of PCB are plastic material. Deformation of both metal chips are curly. Evacuation trajectory of chips is spiralling up along the flute and being pitched out. Composite material of resin and glass fiber of PCB is anisotropic material, whose chips are granular and evacuation form is diffusing.

The maximum thrust force happens when drilling the top copper foil of PCB. Using aluminum entry board can make maximum value a little lower.

Drilling condition is stable and chip evacuation is unobstructed when processing multiple holes because no large fluctuation appears on the thrust force plot. CPK plot shows that the hole accuracy is qualified in the 2000-hit processing.

\section{REFERENCES}

[1] Wang, C.Y., Huang, L.X., Zheng, L.J. and Chang, M. (2010), "Review of micro-drilling PCB \& key technology", Tool Engineering, Vol. 44 No. 1, pp. 3-10. 
[2] Shi, H.Y., Lin, X.K., Wang, Y. (2017) "Characterization of drill bit breakage in PCB drilling process based on high-speed video analysis", Circuit World, Vol. 43, No.3, pp.89-96.

[3] Mellinger, J.C., Ozdoganlar, O.B., DeVor, R.E., Kapoor, S.G. (2002). "Modeling Chip-Evacuation Forces and Prediction of Chip-Clogging in Drilling", Journal of Manufacturing Science and Engineering, Vol. 52, No. 3, pp. 605-614.

[4] Ogawa, K., Aoyama, E., Inoue, H. (1997), "Investigation On cutting mechanism in small diameter drilling for GFRP (thrust force and surface roughness at drilled hole wal1)", Composite Structure, Vol.38, pp. 343-350.

[5] Watanabe, H., Tsuzaka, H. and Masuda, M. (2008), "Microdrilling for printed circuit boards (PCBs) influence of radial run-out of micro-drills on hole quality", Precision Engineering-Journal of the International Societies for Precision Engineering and Nanotechnology, Vol. 32, No. 4, pp. 329-335.

[6] Huang, L.X. (2015), "Investigation of chip formation and burr control in PCB fixture hole", Circuit World, Vol. 41, No. 2, pp. 61-69.

[7] Wang, M.H., Sun, G.Q. (2013), "Finite Element Analysis of the Effect of Chisel Edge on Drilling Composite Laminates", Machinery Design \& Manufacture, Vol.6, pp.237- 243.

[8] Tang, Y., Ma. H.Q., Wu. Q. (2009), "Simulation of Thrust Force and Torque for Micro Hole Drilling", Tool Engineering, Vol. 43 No. 6, pp. 61-66. 